\title{
IMPLEMENTASI SPARQL DENGAN FRAMEWORK JENA FUSEKI UNTUK MELAKUKAN PENCARIAN PENGETAHUAN PADA MODEL ONTOLOGI JALUR KLINIS TATA LAKSANA PERAWATAN PENYAKIT KATARAK
}

\author{
Lalu Mutawalli' ${ }^{1}$, Indi Febriana Suhriani ${ }^{2}$, Supardianto ${ }^{3}$ \\ ${ }^{1}$ Sistem Informasi, STMIK Lombok \\ ${ }^{2}$ Matematika, Universitas Gadjah Mada \\ ${ }^{3}$ Teknik Informatika, Universitas Islam Indonesia \\ Jln. Basuki Rahmat No.105 Praya Lombok Tengah 83511 \\ Jln. Bulaksumur, Sleman Yogyakarta 55281 \\ Jln. Kaliurang KM.14.5 Sleman Yogyakarta 55281 \\ ${ }^{1}$ laluallistilo@gmail.com, 2indifebriana94@gmail.com, ${ }^{3}$ odyputra88@gmail.com
}

\begin{abstract}
The prevalence of cataracts in Indonesia is very high, this can affect the quality of life, productivity and social aspects will cause the nation's economy to be in a low-level position. Cataract problems certainly need to be considered more, however, on the other hand, the lack of experts (doctors) is an obstacle especially outside the city. Uneven distribution of experts will complicate the conditions for solving problems. With these conditions, a semantic-based information technology approach is needed regarding the treatment of patients with cataracts. Semantic information can provide knowledge to non-physician health workers, this will certainly facilitate the process of prevention and prevention of cataracts. In this research, knowledge is modeled using the ontology concept. We have built an ontology model that can be used as a guide to the management of cataract disease. To extract the built-in ontology model, simple protocol and RDF Language (SPARQL) are used as query languages. Apache Jena Fuseki is used to simplify the process of evaluating knowledge.
\end{abstract}

Keywords : Ontology, modeling, clinic, catarac

\begin{abstract}
Abstrak
Prevalensi katarak di indonesia sangat tinggi, hal ini dapat mempengaruhi kualitas kehidupan, produktifitas dan aspek sosial. Hal ini akan menyebabkan penempatan posisi level ekonomi bangsa menjadi rendah. Permasalahan katarak tentu perlu untuk lebih diperhatikan, akan tetapi, di lain sisi kurangnya tenaga ahli (dokter) menjadi kendala khusunya di luar perkotaan. Persebaran tenaga ahli yang tidak merata akan mempersulit kondisi dalam melakukan penyelesaian masalah. Dengan kondisi tersebut dibutuhkan sebuah pendekatan teknologi informasi berbasis semantik tentang tatalaksana perawatan penderita penyakit katarak. Informasi bersifat sematik dapat memberikan pengetahuan pada tenaga kesehatan non-dokter, ini tentu akan mempermudah proses penanggulangan dan pencegahan penyakit katarak. Pada penelitian ini dimodelkan pengetahuan dengan menggunakan konsep ontologi. Kami telah membangun model ontologi yang dapat digunakan sebagai panduan tata laksana perawatan penyakit katrak. Untuk melakukan ekstraksi terhadap model ontologi yang telah dibagun maka digunakan simple protocol and RDF Language (SPARQL) sebagai bahasa query. Apache jena fuseki digunakan untuk mempermudah proses evaluasi terhadap pengetahuan.
\end{abstract}

Kata kunci : Ontologi, model, klinis, katrak. 


\section{Pendahuluan}

Setiap lima detik ditemukan satu orang di dunia menderita kebutaan. Terdapat lebih dari tujuh juta orang menjadi buta setiap tahun. Katarak merupakan penyebab utama kebutaan (WHO, 2017). Kebutaan yang disebabkan oleh katarak di Indonesia menurut Departemen Kesehatan adalah sebanyak delapan puluh persen (DEPKES, 2017). Prevalensi katarak di indonesia sangat tinggi, hal ini dapat mempengaruhi kualitas kehidupan, produktifitas dan aspek sosial ini akan menyebabkan ekonomi bangsa pada posisi level yang rendah (PERDAMI, 2017).

Permasalahan katarak tentu perlu untuk lebih diperhatikan, akan tetapi disisi lain kurangnya tenaga ahli (dokter) menjadi kendala di indonesia khusunya di luar perkotaan. Persebaran tenaga ahli yang tidak merata akan mempersulit kondisi dalam melakukan penyelesaian masalah. Dengan kondisi tersebut dibutuhkan sebuah pendekatan teknologi informasi semantik tentang tatalaksana perawatan penderita penyakit katarak. Dengan informasi bersifat sematik dapat memberikan pengetahuan pada tenaga kesehatan non-dokter, ini tentu akan mempermudah proses penanggulangan penyakit katarak.

Teknologi semantik dapat menghimpun pengetahuan-pengetahuan yang telah dilakukan oleh dari para ahli yang terhimpun dalam suatu konsorsium (Balke, 2011). Kesepakatan tersebut dapat digunakan sebagai standar atau acuan dalam memodelkan pengetahuan perawatan penyakit katarak. Ontologi merupakan istilah yang digunakan untuk merujuk pemahaman bersama (Uschold \& Gruninger, 1996).

Ontologi sebagai konsep dalam memodelkan pengetahuan telah di implementasikan pada beberapa penelitian. Ontologi digunakan untuk memodelkan pengetahuan sebagai acuan dalam mendiagnosa penyakit infeksi tropis (Mutawalli, 2017). Untuk membantu proses monitoring implementasi clinical pathway penanganan penyakit dikembangkan sebuah model ontologi untuk membantu sistem memiliki pengetahuan dalam mengaudit tindakan medis yang dilakukan oleh dokter, perawat, nutrisionis, dan apoteker (Fudholi \& Mutawalli, 2018). Pengembangan tata laksana perawatan dengan sistem sematik untuk membantu dalam memahami clinical data. Sistem semantik yang dikembangkan menggunakan ontologi sebagai konsep pemodelan pengethuan digunakan untuk melakukan proses penalaran (Wang, et al., 2014).

Beberapa penelitian sebelumnya telah berhasil membangun model pengetahuan tata laksana perawatan medis. Oleh karenanya, pada penelitian ini kami mengusulkan ontologi sebagai konsep membangun arsitektur informasi. Kasus pada penelitian ini di hususkan karena secara prinsif setiap kasus tidak dapat digeneralisir, akan tetpai setiap ontologi yang telah dibangun dapat diintegrasikan. Untuk mempermudah proses pencarian informasi yang telah dibentuk, maka digunakan bahasa Simple Protocol and RDF Query Language (SPARQL) dengan framework Apache Jena Fuseki untuk melakukan ekstraksi pengetahuan pada model yang telah dibuat.

\section{Tinjuan Pustaka}

Jalur klinis adalah merupakan pedoman tenaga medis dalam melakukan intervensi terhadap pasien. Penentuan jalur klinis sangat penting untuk dilakukan pemodelan. Model yang dibangun secara sematik dengan konsep ontologi yang membuat pengetahuan pada sistem akan menjadi dinamis. Dinamis yang dimaksud adalah mudah untuk diintegrasi dengan ontologi sebelumnya dan dapat akses dengan tools multiplatform.

A. Penelitian terdahulu

Pemodelan jalur klinis berbasis ontologi telah dibangun oleh beberapa peneliti sebelumnya. Danial mengembangkan clinical pathway berbasis ontologi untuk memudahkan manajemen tata laksana perawatan pasien penyakit kanker prostat (Danial \& Abidi, 2009). Wang menggabungkan standar rencana perawatan dan prosedur perawatan praktis sebagai dasar membangun pengetahuan ontologi (Wang, et al., 2014). Waqila mebuat model ontologi untuk memberikan informasi jenis intervensi tenaga medis pada penderita penyakit kardiovaskular (Waqilla \& Razzak, 2016). Model ontologi untuk membangun pengetahuan sistem dalam memprediksi biaya perawatan pasien (Tehrani, et al., 2013).

\section{B. Peyakit katrak}

Katarak dapat didefinisikan sebagai segala jenis kekeruan yang terjadi pada mata. Manifestasi klins, akibat opasitas lensa, terdapat berbagai gangguan (Tanto, et al., 2014), termasuk:

1) Penurunan tajam pengelihatan;

2) Penurunan sensitivitas kontras, pasien mengeluhkan sulitnya melihat benda di luar ruangan pada cahaya terang;

3) Pergeseran kearah miopa, normalnya, pasien usia lanjut akan mengeluhkan perubahan hyperopia.

4) Diplopia monocular, satu bagian lensa mengalami kekeruahan dengan bagian lensa lainnya; 
5) Sensasi silau;

C. Ontologi

Ontologi adalah istilah yang digunakan untuk merujuk pemahaman bersama dari beberpa domain. Ontologi digunakan sebagai kerangka pemersatu untuk pemecahan suatu permasalahan. Kegunaan ontologi secara umum sebagai controller vocabulary, semantic interoperability, knowledge sharing, dan reuse (Gruber, 1993). Davies menjelaskan manfaat ontologi, yaitu:

1. Menjelaskan domain secara eksplisit;

2. Berbagi pemahaman dari informasi yang tersetruktur.

3. Penggunaan ulang domain pengetahuan

D. SPARQL

Simple Protocol and RDF Query Language (SPARQL) adalah bahasa query untuk RDF. Graph $R D F$ terdiri dari triple yang terbentuk dari subjek, predikat dan objek, $R D F$ dapat di definisikan sebagai konsep dan konsep (W3C, 2008). SPARQL menyediakan fasilitas sebagai berikut:

1. Mengekstrak informasi dalam bentuk URL, blank node dan literal;

2. Mengekstrak RDF subgraph;

3. Membangun graph RDF baru berdasarkan query graph.

Bahasa query SPARQL didasari oleh pencocokan pola graph, pola graph sederhana adalah pola triple seperti triple $R D F$. Menggabungkan triple pattern dapat memberikan basic graph patten agar memenuhi pola. Query dapat mengekstraksi informasi dari satu atau lebih graph dan membatasi pencocokan pola. Berikut adalah contoh query sederhana menunjukkan query SPARQL untuk menemukan judul buku dari informasi yang diberikan graph $R D F$. Query terdiri dari dua bagian yaitu, klausa SELECT dan WHERE.

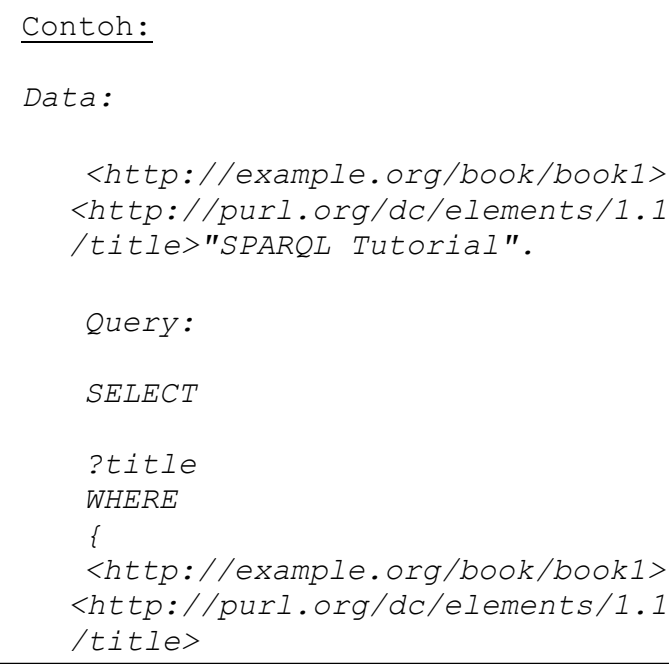

ISSN. 2620-6900 (Online) 2620-6897 (Cetak)
E. Apache Jena Fuseki

Apache Jena (atau disingkat dengan Jena) adalah framework java. Jena dapat digunakan secara open source untuk membangun sistem maupun web semantic. Framework ini terdiri dari berbagai Application Programming Interface (API) yang berintegrasi untuk memproses data Resource Description Framework (RDF). RDF adalah standar untuk menggambarkan sumber daya. Sumber daya yang dimaksud adalah segala sesuatu yang dapat diidentifikasi (Jena, 2011).

Jena memiliki metode untuk membaca dan menulis $R D F$ sebagai $X M L$. Ini dapat digunakan untuk menyimpan $R D F$ ke file dan kemudian membacaya kembali. Contoh kode untuk membuat model sederhana:

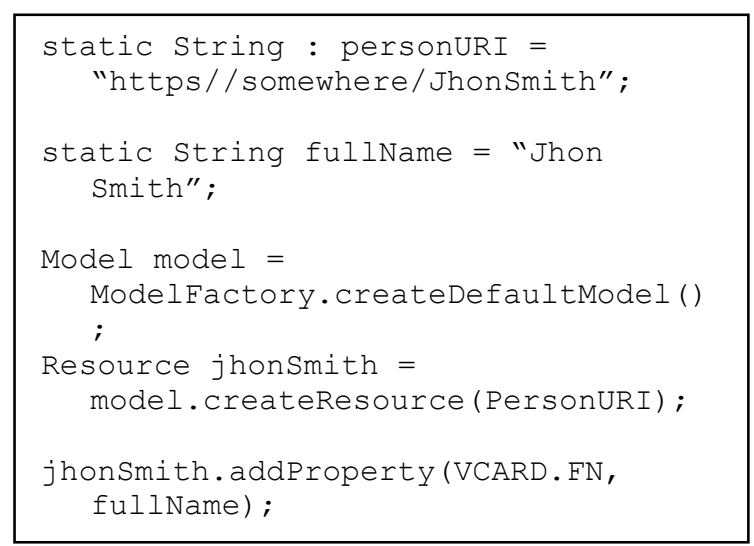

\section{Metodologi Penelitian}

Tahapan pada penelitian ini seperti pada Gambar 2.1. Tahapan dimulai dari proses identifikasi masalah, menetapkan tujuan penelitian, melakukan pengumpulan data, mengolah data, memodelkan data menjadi pengetahuan, dan evaluasi pengetahuan.

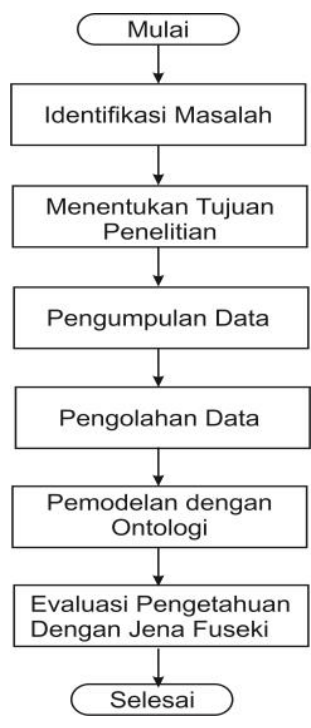

Gambar 2.1 tahapan penelitian 


\section{A. Identifikasi Masalah}

Terdapat beberapa penyakit yang telah dibuatkan standar tatalaksana di rumah sakit islam harapan anda kota tegal. Akan tetapi, dalam penelitian ini akan memfokuskan pada penyakit katarak.
D. Pengolahan data

Dokumen jalur klinis dimasukkan dimodelkan menjadi basis pengetahuan. Tools protégé digunakan untuk membentuk arsitektur pengetahuan. Gambar 2.2 merupakan tampilan utama tools protégé.

Gambar 2.2 Tampilan utama tools protégé

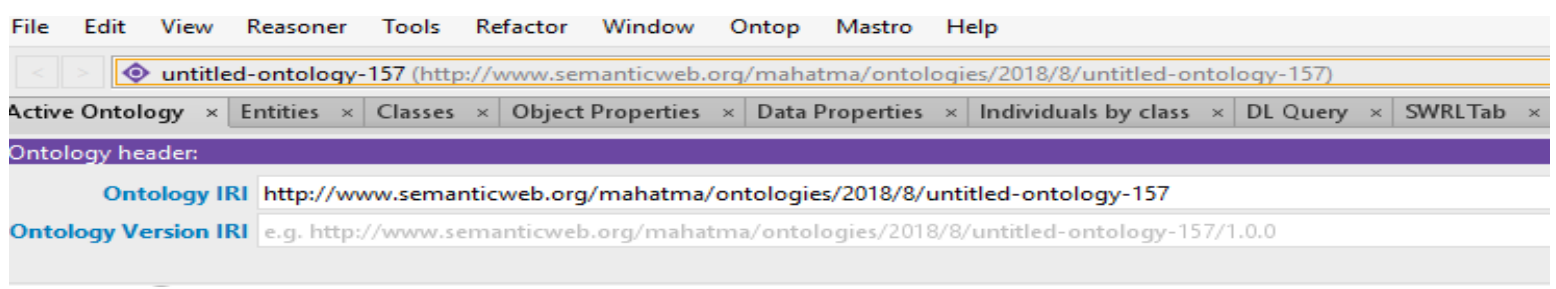

B. Menentukan tujuan penelitian

Pada tahap penetapan tujuan ini menjelaskan justifikasi permasalahan yang ingin digapai. Kasus pada penelitian ini menggunkan standar tatalaksana intervensi untuk tipe rumah sakit dengan tipe B dan C.

\section{Pengumpulan Data}

Pengumpulan data dilakukan dengan teknik observasi, wawancara. Data sekunder yang didapatkan berupa form dokumen jalur klinis tatalaksana intervensi penyakit katarak. Pada tabel 1 merupakan isian yang terdapat pada dokumen jalur klinis perawatan penyakit katarak.

Tabel 1. Data jalur klinis penyakit katarak

\begin{tabular}{|c|c|c|}
\hline No & Kegiatan & $\begin{array}{c}\text { Penangungg } \\
\text { Jawab }\end{array}$ \\
\hline 1. & Asesmen awal & Dokter, Perawat \\
\hline 2. & Laboratorium & Dokter \\
\hline 3. & Konsultasi & Dokter \\
\hline 4. & Asesmen lanjutan & $\begin{array}{l}\text { Dokter, perawat, } \\
\text { gizi, farmasi }\end{array}$ \\
\hline 5. & Diagnosis & $\begin{array}{l}\text { Dokter, perawat, } \\
\text { gizi, farmasi }\end{array}$ \\
\hline 6. & Discharge Planing & Dokter \\
\hline 7. & Edukasi terintegrasi & $\begin{array}{l}\text { Dokter, perawat, } \\
\text { gizi, farmasi }\end{array}$ \\
\hline 8. & $\begin{array}{l}\text { Terapi Medika } \\
\text { Mentosa }\end{array}$ & Dokter \\
\hline 9. & Tatalaksana Intervensi & $\begin{array}{l}\text { Dokter, perawat, } \\
\text { gizi, farmasi }\end{array}$ \\
\hline 10. & $\begin{array}{l}\text { Monitoring dan } \\
\text { Evaluasi }\end{array}$ & $\begin{array}{l}\text { Dokter, perawat, } \\
\text { gizi, farmasi }\end{array}$ \\
\hline 11. & Mobilisasi/rehabilitasi & $\begin{array}{l}\text { Dokter, perawat, } \\
\text { gizi, farmasi }\end{array}$ \\
\hline 12. & Outcome/hasil & $\begin{array}{l}\text { Dokter, perawat, } \\
\text { gizi, farmasi }\end{array}$ \\
\hline 13. & Kriteria Pulang & Dokter \\
\hline 14. & Rencana Pulang & Dokter \\
\hline
\end{tabular}

ISSN. 2620-6900 (Online) 2620-6897 (Cetak)
E. Pemodelan pengetahuan

Rekayasa ontologi tetang suatu harus mempertimbangkan wujudnya dan keberadaanya. Matematika memiliki sifat dasar yang diungkapkan dalam kata sebagai wujudnya (Davies, et al., 2006),

F. Evlausi pengetahuan

Bahasa SPARQ digunakan untuk melakukan query. Dengan memanfaatkan framework jena fuseki sebagai tools melakukan simulasi pencarian pengetahuan yang terkandung di dalam pengetahuan yang telah di modelkan.

\section{Hasil dan Pembahasan}

A. Implementasi studi kasus

Ontologi jalur klinis terdiri dari tiga aspek yang dipetakan kedalam kelas: kegiatan, person, penyakit. Kelas kegiatan merupakan segala intervensi yang dilakukan oleh tenaga medis terhadap pasien yang terkena penyakit katrak. Kelas person merupakan orang dan profesi yang terlibat dalam melakukan praktek perawatan. Kelas penyakit adalah penyakit katarak. Gambar 4.1 memaparkan daftar kelas yang terdapat pada model ontologi jalur klinis perawatan penyakit katarak.

Kegiatan

- Asesmen_Awal

1. Asesmen_Lanjutan

-.. Diagnosis

- Edukasi_Terintegrasi

○ Konsultasi $\equiv$ Dokter_Ane

Kriteria_Pulang

Laboratorium

Mobilisasi_Rehabilitasi

Monitoring_Evaluasi

Outcome

Rencana_Pulang

Tatalaksana_Intervensi

-.. Terapi_Medika_Mentosa

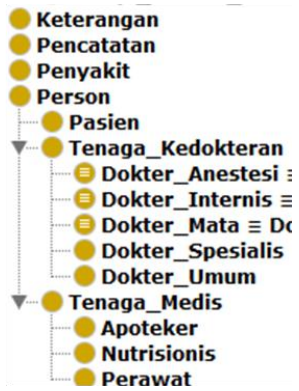

Gambar 4.1 Kelas dalam model jalur klinis 
Pada model jalur klinis perawatan penyakit katarak terdapat object property yang menghubungkan antar kelas. Hubungan antar kelas yang dimaksud adalah kaitan antar kelas dalam praktek intervensi medis. Pada kelas model ontologi terdapat kelas penyakit dan person. Kelas penyakit adalah penyakit katarak dimana pada kelas person terdapat pasien dan dokter dan tenaga medis lainnya. Person pasien memiliki penyakit dimana penyakit tersebut memiliki gejala. Gejala yang muncul menjadi dasar bagi dokter untuk memberikan intervensi perawatan kepada pasien. Gambar 4.2 menampilkan object property pada model jalur klinis penyakit katarak.

\begin{tabular}{|c|c|}
\hline 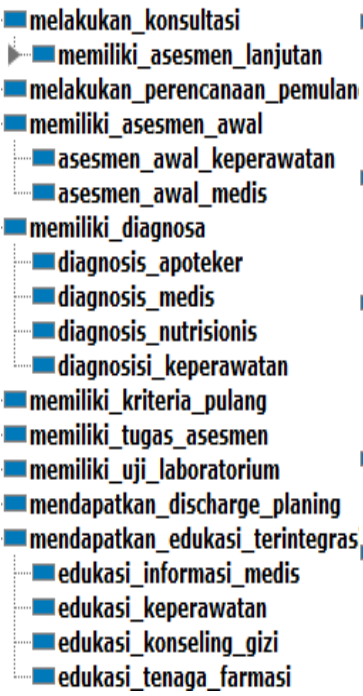 & 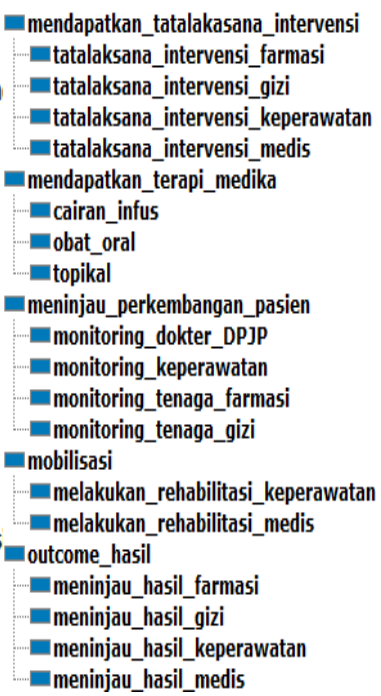 \\
\hline
\end{tabular}

Gambar 4.2 Object Property model jalur klinis
Ontologi jalur klinis yang dibangun memberikan refrensi pengetahuan untuk intervensi penyakit katarak. Ontologi menghubungkan semua aspek yang diamati dalam pengembangan layanan kesehatan, termasuk koordinasi antar tenaga medis dan petugas medis. Pengetahuan dapat digunakan untuk menentukan parameter intervensi, seperti tindakan yang diberikan, pemberian obat (terutama antibiotik), lama perawatan yang dibutuhkan, analisis penyakit, investigasi dan semua jenis tenaga medis dan petugas medis dalam melakukan perawatan.

\section{B. Diskusi dan evaluasi}

Kami mengembangkan model ontologi yang mendukung proses tata laksana perawatan pasien dengan penyakit katarak. Untuk mengevaluasi ontologi yang diusulkan, kami menggunakan SPARQL dan framework apache jena fuseki untuk menunjukkan kelengkapan jalur klinis dalam ontologi. Berdasarkan empat cakupan kelas, yaitu: kegiatan, person, penyakit, pencatatan. Empat cakupan tersebut kemudian di elaborasi menggunakan studi kasus yang digunkan dalam diskusi berikutnya.

Langkah pertama melakukan upload dataset ontologi jalur klinis yang telah dibanun menggunakan tools protégé. Masukkan dataset tersebut pada sistem yang apache jena fuseki telah dikembangkan, Gambar 4.4 menunjukkan dataset telah berhasil diupload ke dalam sistem jena, proses berhasil ditandai dengan keterangan result success.

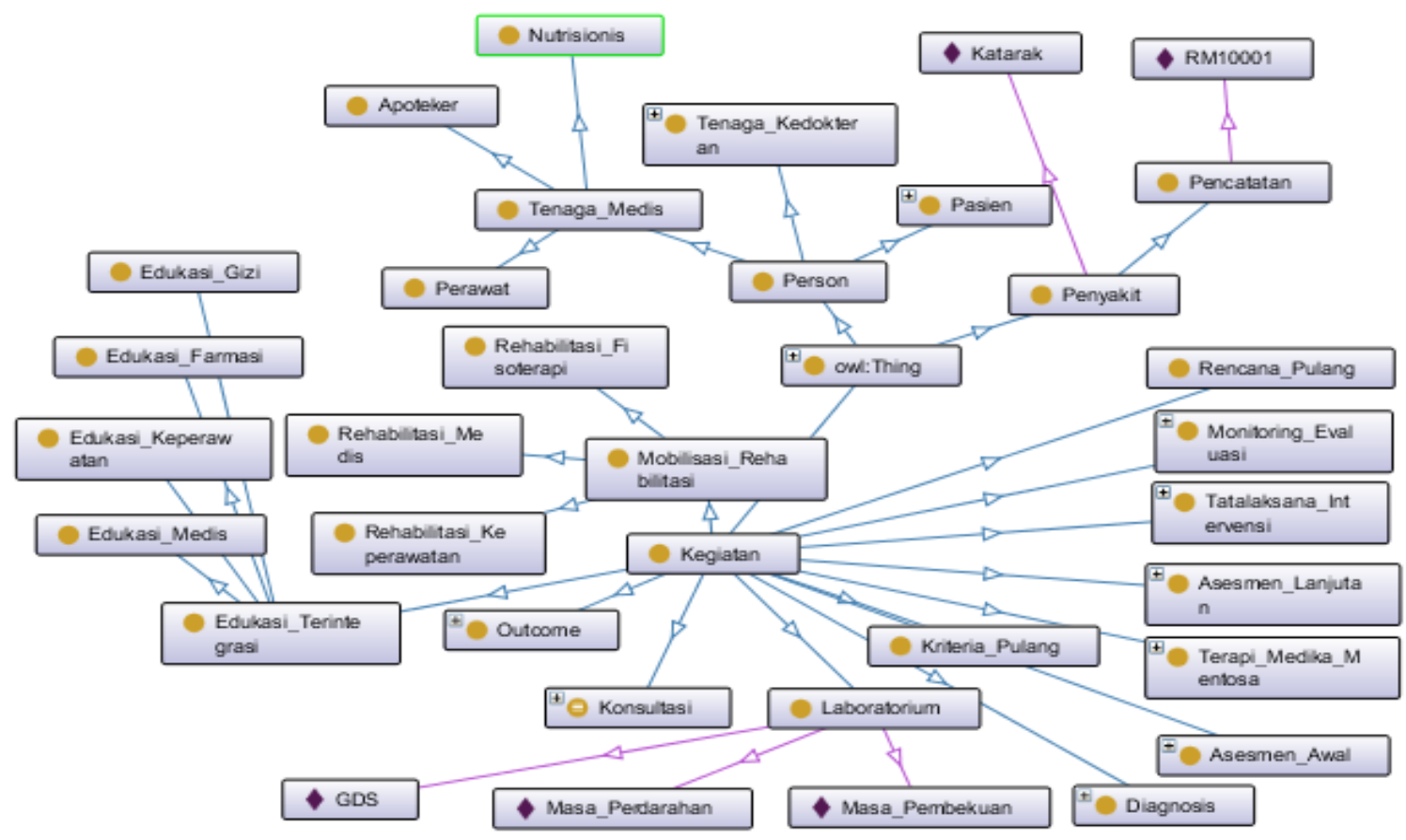

ISSN. 2620-6900 (Online) 2620-6897 (Cetak) 


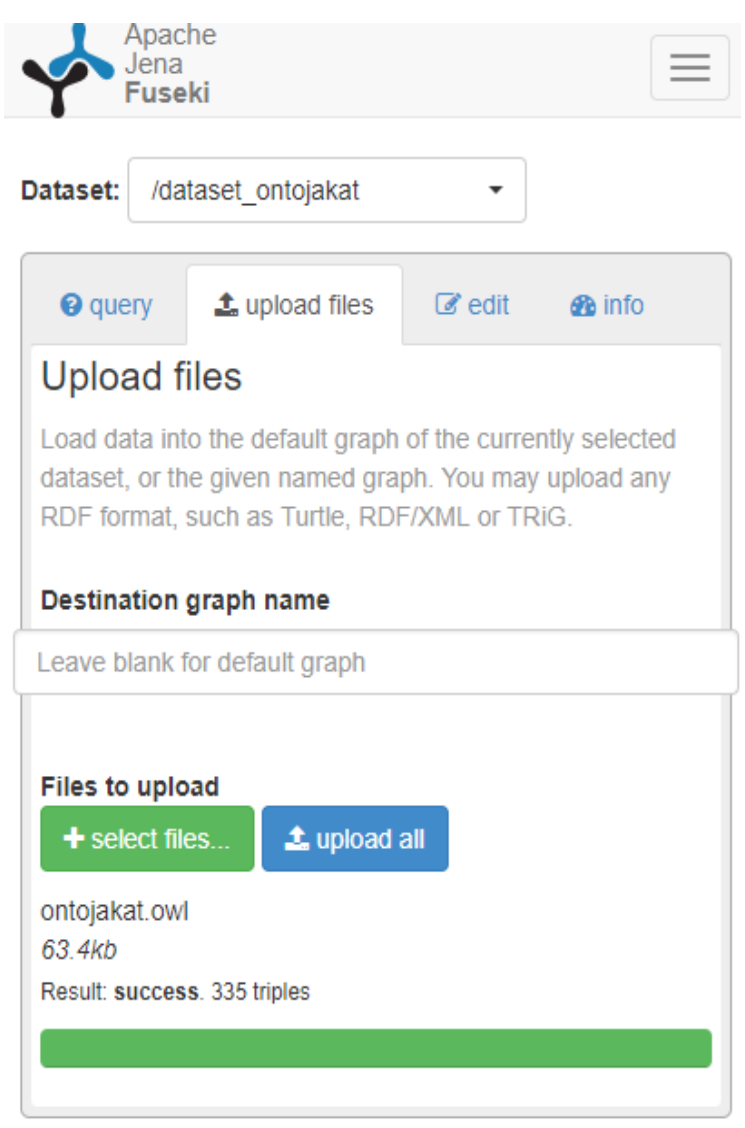

Gambar 4.4 Upload dataset pada jena fuseki

\section{1) Kegiatan}

Evaluasi jenis kegiatan bertujuan untuk mendapatkan informasi tentang jenis intervensi yang telah dilakukan terhadap pasien dengan kode rekam medis RM10001. Pada studi kasus di Tabel 2. Kami memasukkan beberapa jenis intervensi yang telah diberikan. Untuk uji coba kami hanya memasukkan tindakan yang dilakukan oleh dokter dan perawat.

Tabel 2. Evaluasi intervensi yang telak dilakukan

\begin{tabular}{|c|c|c|}
\hline No & $\begin{array}{l}\text { Konteks } \\
\text { pencarian }\end{array}$ & SPARQL \\
\hline 1 & $\begin{array}{l}\text { Intervensi } \\
\text { penyakit } \\
\text { katarak }\end{array}$ & $\begin{array}{l}\text { PREFIXcp:<http://www. } \\
\text { ontojakat.org/onologi/ja } \\
\text { lur_klinis/tatalaksana/k } \\
\text { atara\#> } \\
\text { SELECT DISTINCT } \\
\text { ?aktivitas } \\
\text { ?deskripsi_aktivitas } \\
\text { WHERE \{ } \\
\text { cp:RM10001 } \\
\text { ?aktivitas } \\
\text { ?deskripsi_aktivitas }\end{array}$ \\
\hline
\end{tabular}

ISSN. 2620-6900 (Online) 2620-6897 (Cetak)

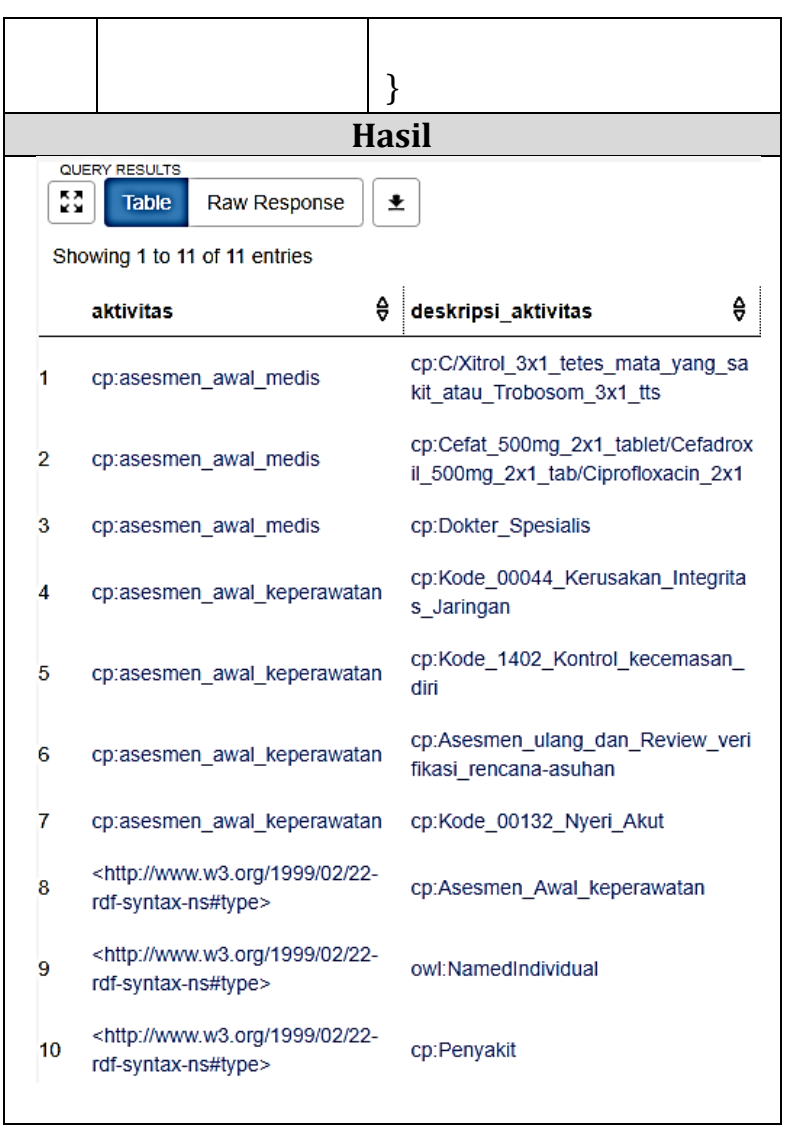

\section{2) Person}

Evaluasi person bertujuan untuk mengidentifikasi biodata dari setiap individu. Ini penting untuk dilakukan karena pada kelas person terdapat person merupakan pasien dengan person adalah seorang yang brtugas sebagai dokter. Pada bagian ini kami menampilkan biodata person yang berisikan biodata pasien. Query dan hasil query dapat dilihat pada tabel 3. Biodata pasien. 
Tabel 3. Evaluasi biodata pasien

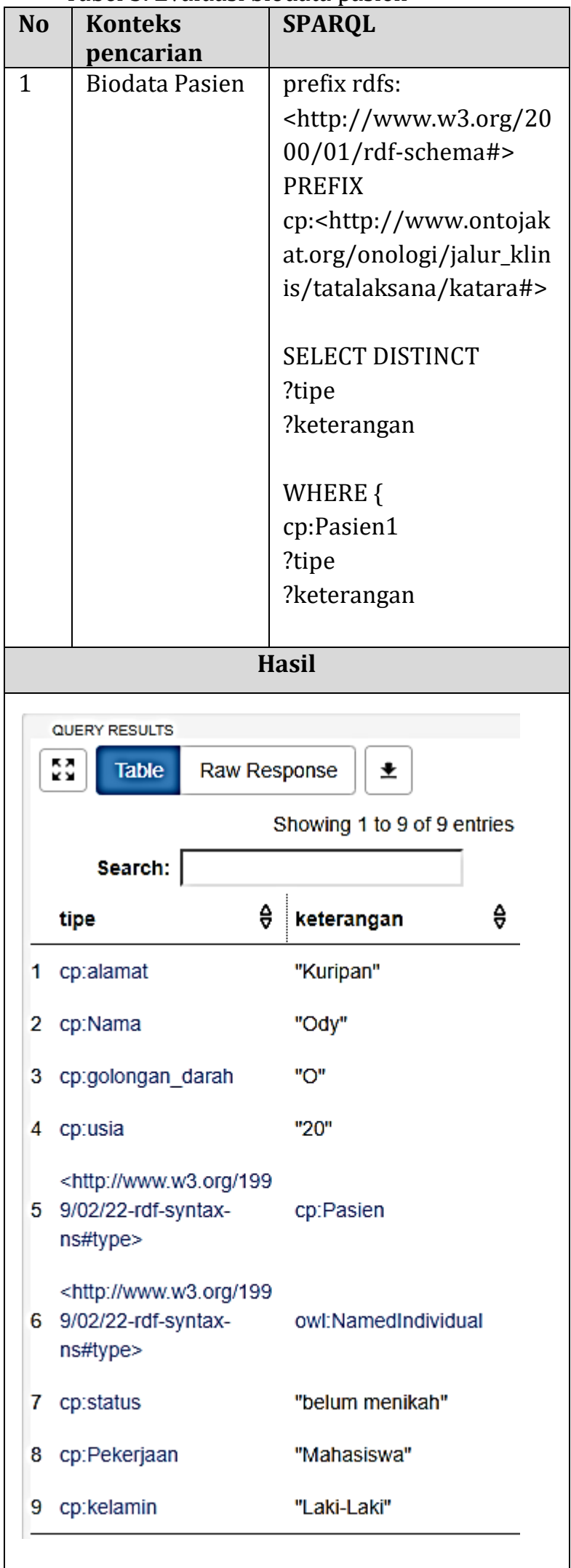

3) Penyakit

Evaluasi penyakit bertujuan untuk mendapatkan informasi tentang jenis tindakan yang akan diberikan pada pasien. Ini penting guna membandingkan tindakan yang akan diberikan dengan tindakan yang telah dilakukan. Pada kasus di penelitian ini, kami memasukkan jenis intervensi yang dilakukan oleh setiap profesi dokter, perawat, nutrisonis, dan farmasi. Tabel 4. Menunjukkan daftar intervenesi yang harus dilakukan oleh masing-masing profesi.

Tabel 4. Evaluasi intervensi penyakit katarak

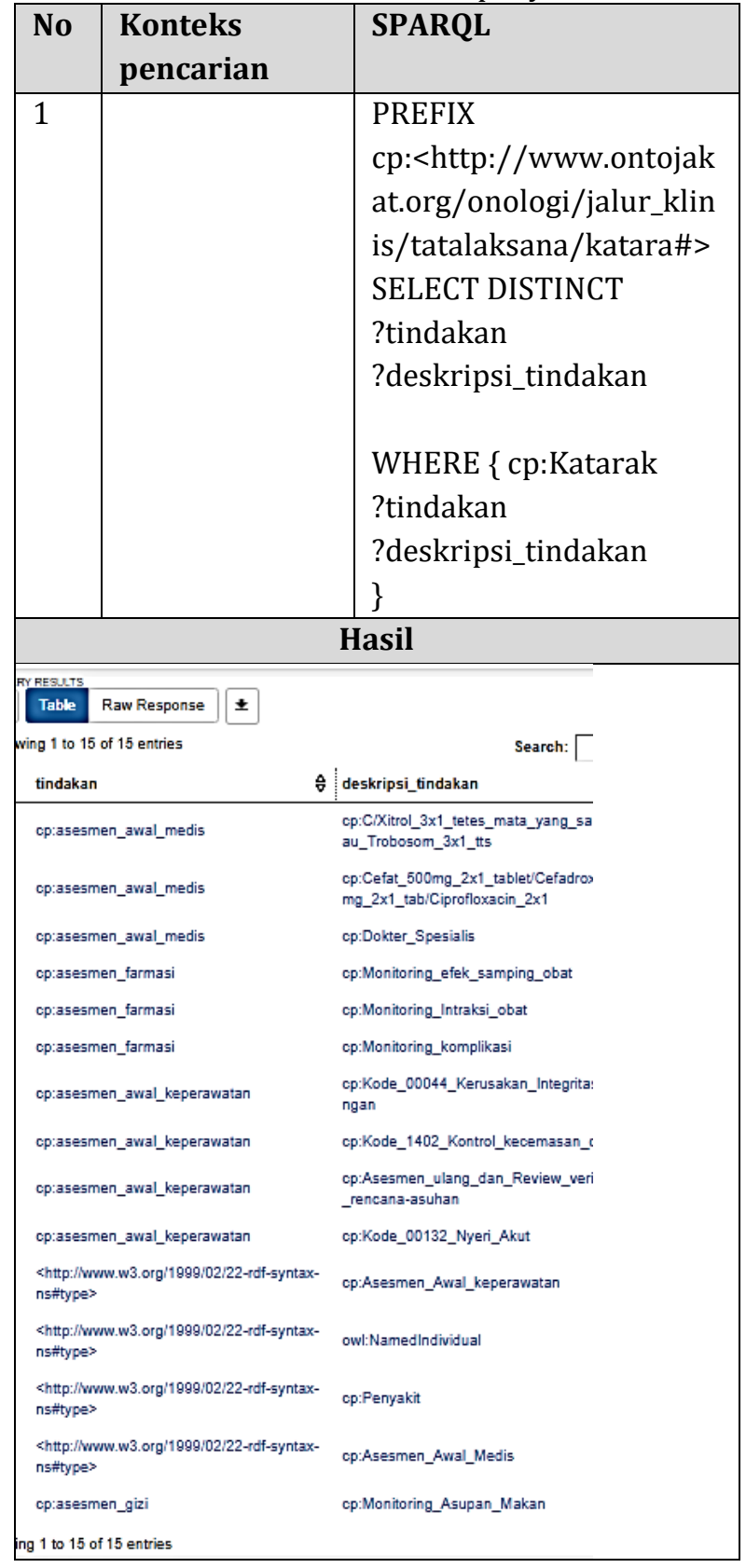




\section{Kesimpulan dan saran}

A. Kesimpulan

Jalur klinis adalah alat untuk mendokumentasikan perjalanan perawatan pasien. Untuk meningkatkan kualitas praktik, ontologi telah digunakan sebagai representasi semantic yang kaya dan dapat memodelkan jalur klinis. Dalam makalah ini, kami merancang ontologi jalur klinis. Model yang diusulkan terdiri dari tiga aspek.

Aspek kegiatan yang sebagai inti dari pengetahuan jalur klinis pasien; person sebagai individu dan kelompok yang menjalankan praktek kesehatan dan pasien; penyakit adalah domain sebagai kasus yang akan di bantu proses penanganannya. Model yang telah diusulkan telah dievaluasi untuk menunjukkan kesesuaian model ontologi dalam praktek jalur klinis terkait perawatan penyakit katarak.

B. Saran

Penelitian ini menghasilkan model pengetahuan jalur klinis untuk perawatan penyakit katarak. Model ontologi membentuk tiga kelas yaitu, kelas kegiatan, kelas person, dan kelas penyakit. Keterbatasan pada penelitian ini adalah model belum dapat memberikan pengetahuan tentang rekomendasi obat dan melakukan perbandingan terhadap intervensi yang telah dilakukan dengan intervensi medis yang seharusnya dilakukan. Untuk pengembangan lebih lanjut, kami menyarankan model ontologi dapat dilengkapi dengan kekurangan yang kami dapatkan.

\section{Daftar Pustaka}

[1] Balke, W. T., 2011. Knowledge-Based Systems and Deductive Databases. Artifical Intillegence, 1(1), pp. 89-97.

[2] Danial, A. \& Abidi, S. R., 2009. Computerizing Clinical Pathways: Ontology Based Modeling and Execution. Medical Informatic, 1(1), pp. 643-647.

[3] Davies, J., Studer, R. \& Waren, P., 2006. Semantic Web Technologies Trend and Research in Ontology Based System. First ed. London: Jhon Wiley.

[4] DEPKES, 2017. Katarak Penyebab Utama Kebutaan di Indonesia. [Online] Available at: http://www.depkes.go.id/article/view/171 00400003/katarak-penyebab-utamakebutaan-di-indonesia.html.

[5] Fudholi, D. H. \& Mutawalli, L., 2018. An Ontology Model for Clinical Pathway Audit. Yogyakarta, IEEE.
[6] Fudholi, D. H. \& Mutawalli, L., 2018. A Lightweight Semantic-Based Medical Document Retrival. Bandung, IEEE.

[7] Gruber, R. T., 1993. A Translation Approach to Portable Ontology Spesifications. Knowledge Acuisition, 1(1), pp. 199-208.

[8] Jena, 2011. Getting Started WIth Apache Jena.

[Accessed 20 Januari 2019].

[9] Mutawalli, L., 2017. Pemodelan dan Pengembangan Sistem Pendeteksian Penyakit Infeksi Tropis Berbasis Ontologi. Jurnal Informatika dan Rekayasa Elektronik, 1(1), pp. 7-12.

[10] Kalaena, L. S., \& Bagye, W. (2018). Implementasi Network Attached Storage (NAS) Menggunakan Freenas Pada STMIK Lombok. Jurnal Manajemen Informatika dan Sistem Informasi, 1(1), 6-10.

[11] Khairul Imtihan. "Perencanaan Strategi Sistem Informasi Pendidikan Pada Sekolah Tinggi Manajemen Informatika dan Komputer (STMIK) Lombok." Bianglala Informatika 3.2 (2015).

[12] Imtihan, Khairul, Rabiatul Hadawiyah, and Hasyim Asyari-STMIK Lombok. "Sistem Informasi Penggajian Guru Honorer Menggunakan Konsep Agile Software Development dengan Metodologi Extreme Programming (XP) pada SMK Bangun Bangsa." IJNS-Indonesian Journal on Networking and Security 7.2 (2018).

[13] PERDAMI, 2017. Vision 2020 di Indonesia. [Online]

Available at: https://perdami.id/vison2020-indonesia

[Accessed 18 Januari 2019].

[14] Tanto, C., Liwang, F., Hanifan, S. \& Pradipta, E. A., 2014. Kapita Selekta Kedokteran. Edisi IV ed. Jakarta: Media Aesculapius.

[15] Tehrani, J., Liu, K. \& Michel, V., 2013. Ontology Modeling for Generation of Clinical Pathway. Journal of Industrial Enginerring and Management, 12(2), pp. 442-456.

[16] Uschold, M. \& Gruninger, M., 1996. Ontologies : Principles, Methods and Applications. Knowledge Engineering Review, 11(2), pp. 93-136.

[17] W3C, 2008. SPARQL Query Language for RDF. [Online] Available at: https://www/w3.org/TR/rdfsparql-query

[Accessed Januari 19 2019].

[18] Wang, H. Q., Zhou, T. S., Tian, L. l. \& Li, J. S., 2014. Creating hospital-specific customized clinical pathways by applying semantic 
reasoning to clinical data. Journal of Biomedical Informatics, 52(2), pp. 354-363.

[19] Waqilla, M. \& Razzak, M. I., 2016. An Ontology Based Framework Aiming to Support Cardiac Rehabilitation Program. Artificial Intillegence, 10(2), pp. 23-32.
[20] WHO, 2017. Blindness and Vison Impairment Prevention. [Online] Available at: http://www.who.int/blindness/causes/prio rity/en/index1.html [Accessed 2018 September 7]. 